\title{
FLORA MEDICINAL EMPLEADA POR EL POBLADOR DEL DISTRITO DE HUANCHACO, LA LIBERTAD, PERÚ.
}

\section{MEDICINAL FLORA USED BY THE RESIDENT OF THE DISTRICT OF HUANCHACO, LA LIBERTAD, PERU.}

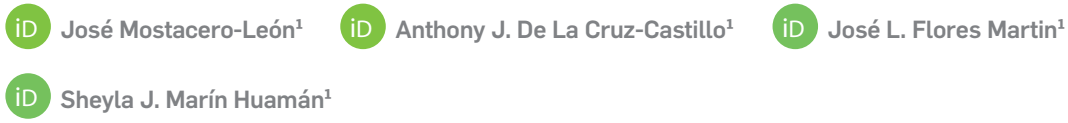

${ }^{1}$ Universidad Nacional de Trujillo, Perú.

Correspondencia:

Dr. José Mostacero León

jmostacero@unitru.edu.pe

\section{RESUMEN}

Perú país megadiverso, alberga una extraordinaria riqueza de especies vivientes en general y de Flora en particular, empleada por el hombre a través de su historia como alimento, vestido, combustible, madera, entre otros; pero sobre todo para curar y/o aliviar sus dolencias y/o enfermedades; sabiduría etnobotánica ancestral, impartida inicialmente por los "Hampicamayoc", "Oquetlupuc", "Sircac", persistiendo hasta hoy en la memoria de los "curanderos" y "abuelitas"; pero que lamentablemente se viene perdiendo por la falta de comunicación y registro. Por ello se planteó como objetivo de la presente investigación realizar el inventario de la Flora medicinal, empleada por el poblador del Distrito de Huanchaco, La Libertad, Perú; toda vez que resulta importante revalorar este conocimiento ancestral sobre el correcto y eficaz uso de la flora en la cura y/o alivio de muchas enfermedades y/o dolencias. Se aplicaron 96 entrevistas semiestructuradas, empleando la técnica "bola de nieve"; a fin de recabar información sobre las características taxonómicas: Familia, Nombre Científico y común; así como de los caracteres etnomedicinales: parte utilizada, forma de preparación y usos Medicinales. Se reportan 44 especies de plantas medicinales, distribuidas en 22 familias y 42 géneros; donde las: Lamiaceae (5), Asteraceae (4), y Rutaceae (3), Poaceae (3) y Apiaceae (3), destacan por el número de especies.

Palabras clave: Flora medicinal, Huanchaco, Trujillo

\section{ABSTRACT}

Peru, a megadiverse country, houses an extraordinary wealth of living species in general and of Flora in particular, used by man throughout its history as food, clothing, fuel, wood, among others; but above all to cure and / or alleviate their ailments and / or diseases; ancestral ethnobotanical wisdom, initially imparted by the "Hampicamayoc", "Oquetlupuc", "Sircac", persisting until today in the memory of the "healers" and "grandmothers"; but that unfortunately has been lost due to 
the lack of communication and registration. For this reason, the objective of this research was to carry out the inventory of the medicinal Flora, used by the resident of the District of Huanchaco, La Libertad, Peru; since it is important to reassess this ancestral knowledge about the correct and effective use of flora in the cure and / or relief of many diseases and / or ailments. 96 semi-structured interviews were applied, using the "snowball" technique; in order to gather information on the taxonomic characteristics: Family, Scientific and Common Name; as well as ethnomedicinal characters: part used, form of preparation and Medicinal uses. 44 species of medicinal plants are reported, distributed in 22 families and 42 genera; where the: Lamiaceae (5), Asteraceae (4), and Rutaceae (3), Poaceae (3) and Apiaceae (3), stand out for the number of species.

Key words: Medicinal flora, Huanchaco, Trujillo

\section{INTRODUCCIÓN}

Dentro de la riqueza vegetal presente en Perú, resaltan las "plantas medicinales"; cuyas hojas, tallos, raíces y /o frutos contienen alta calidad, de vitaminas, sales minerales, carotenoides, pigmentos antociánicos, que sumados a los alcaloides, polifenoles y terpenoides, procedentes del metabolismo secundario; les confieren propiedades inherentes para prevenir y /o curar un sin número de enfermedades, constituyéndose en recursos promisorios y funcionales para el poblador mundial en general y del Perú en particular (Bhat et al., 2016; Bruneton, 2001; Jatinder et al., 2016; Mostacero, 2017; Mostacero et al., 2019; Magno et al., 2020; Mostacero et al., 2020a).

Especies vegetales conocidas por los antiguos peruanos, quienes desde tiempos inmemoriales las utilizaban, y que con el pasar de los años lograron establecer empíricamente su correcto y eficaz uso para la cura de tal o cual enfermedad; sabiduría ancestral, impartida en un inicio por los "Hampicamayoc", "Oquetlupuc", "Sircac", y que actualmente persiste a través de los "curanderos" y "abuelitas" (Tovar, 2001; Mostacero et al., 2011, Mostacero et al., 2019; Alipio et al., 2020; Ramírez et al., 2020).

De igual manera, es importante recalcar que alrededor del $80 \%$ de la población mundial hace uso de la medicina tradicional; incluyendo los cerca de 390 millones de Latinoamericanos, con unos 50 a 60 millones de origen indígena, que aún emplean medicamentos tradicionales para tratar diversos problemas de salud; toda vez que el uso de plantas medicinales, resulta hoy en día más económico, seguro y de amplia distribución; por lo que día a día va alcanzado un estatus independiente por sobre la medicina o en combinación con la medicina moderna extendiéndose incluso a las culturas extranjeras (Annan y Houghton, 2007; Martin, 2005; Mostacero et al., 2011).

Asimismo, existen un sin número de investigaciones que avalan la efectividad de las plantas medicinales, al combatir alrededor de 350 enfermedades descritas hasta la actualidad; de allí que estudios afirman los beneficios que aportan distintas especies vegetales para la salud; como es, el hecho de disminuir el riesgo de padecer y/o combatir las enfermedades cardiovasculares (Mostacero et al., 2011; Boeing et al., 2012; Cárdenas et al., 2015; Goszcz et al., 2015), la diabetes (Boeing et al., 2012; Wang et al.,2016), la hipercolesterolemia (Mannarino et al., 2014), la resistencia a la insulina (Parikh et al.,2014); así como prevenir, curar y/o aliviar, distintos tipos de cáncer (Freedman et al., 2014; Shigihara et al., 2014; Magadi et al., 2015; Gil et al., 2019), e incluso la Covid-19 (Mostacero et al., 2020b).

Ahora bien, Perú y más específicamente su lado Norte, hoy se constituye en el centro del Eje de Salud de los Andes Centrales; siendo Trujillo la tercera ciudad de mayor población del Perú, caracterizada por su excepcional pluriculturalidad (Agenda 21, 2003), pero que lamentablemente viene siendo aquejada por un sin número de enfermedades, de allí que entre los años 2003-2010 murieron, en 
Trujillo, un total de 90 personas por cáncer de estómago, 50 de cuello uterino, 38 de próstata, 37 colorrectal, 36 pulmón y 30 de mama; por no mencionar el sin número de muertes a causa de enfermedades que afectan al Sistema Nervioso, al Sistema Cardiovascular (obesidad, colesterol y triglicéridos elevados, hipertensión), Diabetes, Sistema Genito-urinario; así como las miles de muertes a causa de la Pandemia Covid-19; cuyos tratamientos son muy caros y fuera del alcance de muchos pobladores Trujillanos en general y del Distrito de Huanchaco en particular; por lo que resulta vital el empleo de plantas medicinales como medicina complementaria (Albújar-Baca, 2014; De La Cruz y Mostacero, 2019).

En tal sentido y conociendo que Huanchaco, es uno de los 12 distritos que conforman la Provincia de Trujillo, que arraiga un rico saber ancestral heredados en esencia por la cultura
Mochica; y que hoy en día lamentablemente se vienen perdiendo; asimismo, no habiendo investigación alguna sobre el uso de plantas medicinales en este distrito; se plantea como objetivo de la presente investigación determinar la flora medicinal empleada por el poblador del Distrito de Huanchaco, La Libertad, toda vez que resulta importante revalorar este saber ancestral en la cura y/o alivio de muchas enfermedades y/o dolencias, así como sentar las bases para futuras investigaciones del tipo aplicadas; fomentando en todo momento el uso sostenible de esta flora promisoria.

\section{MATERIAL Y MÉTODOS Lugar de ejecución}

La presente investigación se realizó en el distrito de Huanchaco, Trujillo, La Libertad, Perú. Ubicado a $08^{\circ} 04^{\prime} 34^{\prime \prime}$ de Latitud sur y $79^{\circ} 06^{\prime} 57^{\prime \prime}$ de Longitud Oeste; a una altitud de 23 m.s.n.m. en la parte Nor Oeste de Trujillo (Fig. 1).

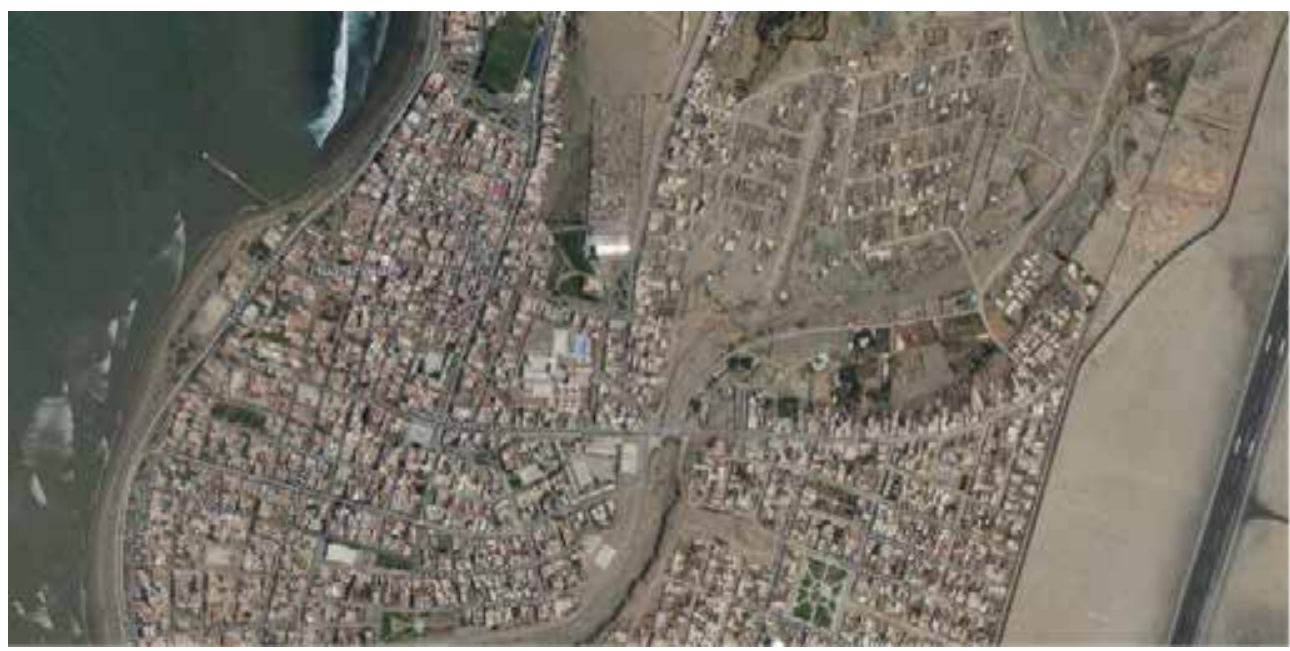

Figura 1. Ubicación del distrito de Huanchaco, La Libertad, Perú (Fuente: Google Earth)

\section{Muestra}

La muestra estuvo constituida por 96 personas, dato obtenido, mediante la fórmula propuesta por Bocanegra et al. (2011), que considera población finita y varianza desconocida, con un error permisible de $10 \%$ y un nivel de confianza del $95 \%$.

$$
\mathrm{n}=\frac{\mathrm{N} Z^{2} p q}{d^{2}(N-1)+Z^{2} p q}
$$


Dónde: n: Tamaño de la muestra; N: Población del estudio: 44806 habitantes (INEI, 2018); p: Proporción de éxito de la característica de interés, igual a $50 \%(0.5)$; q: 1 - P = complemento de P; Z: Coeficiente de confiabilidad al $95 \%$ igual a 1.96; d: Tolerancia de error permisible en la investigación = 0.1 (10 \%).

$$
\mathrm{n}=\frac{(44806) 1.96^{2}(0.5)(0.5)}{0.1^{2}(44806-1)+1.96^{2}(0.5)(0.5)}=96
$$

\section{Técnica e instrumento de recolección de datos}

Se utilizó como instrumento, la entrevista semiestructurada; siguiendo la técnica de "bola de nieve", propuesta por Bailey (1994).

\section{Validación y confiabilidad del instrumento}

Esta se realizó a través del juicio crítico de tres expertos, sumado a la revisión previa de la misma, por los autores de la investigación e informantes de los diferentes grupos de interés. Con las sugerencias recibidas, se realizaron los ajustes pertinentes para obtener la versión definitiva del instrumento.

\section{Criterio de inclusión y exclusión}

Personas mayores de 20 años, habitantes del distrito de Huanchaco y que hayan hecho uso de las plantas medicinales durante el tratamiento y/o cura de alguna enfermedad padecida. Personas que no respondan íntegramente la entrevista o muestren indicios de información falsa.

\section{Procedimientos de recolección de datos}

Para ello se siguió la técnica "bola de nieve", según Bailey (1994); la misma que consistió en entrevistar a al primer informante, catalogado como "conocedor", quien brindó información requerida, referente a nombres vulgares, parte empleada, tipo de preparado, forma de administración y los usos medicinales que les confieren a cada planta; el mismo que al finalizar la entrevista indicó el nombre de la siguiente persona a entrevistar, considerada también "conocedora" en el tema, que al igual que el anterior proporcionó la misma información concerniente al uso que hace de las plantas medicinales. Y así, a modo de "bola de nieve" se repitió este procedimiento para los 94 informantes restantes.

\section{Análisis de datos}

La información obtenida, fue organizada en tablas previamente complementadas con la información presentada en tesis, artículos científicos y libros sobre la materia (Mostacero et al., 2011). De igual manera, los resultados, se plasmaron en gráficos y tablas; empleando el programa Microsoft Excel 2016.

\section{Determinación de la flora medicinal}

Paralelamente a la aplicación de las entrevistas se realizó la colecta de los especímenes botánicos, en compañía de una de las personas conocedoras de la zona. Cabe destacar que las plantas colectadas fueron determinados taxonómicamente por comparación con los registrados en el Herbarium Truxillense (H.U.T.).

También, se hizo uso de claves taxonómicas relacionadas con la vegetación propia del territorio peruano; agenciados continuamente de Los libros Brako y Zarucchi (1993) y Mostacero et al. (2009), así como de los portales virtuales: Trópicos y The Plant List.

\section{Aspectos éticos}

Se tuvo en cuenta en todo momento, contar con el consentimiento de las personas que participarán en la investigación. Asimismo, se respetó el derecho a la privacidad con respecto a la información proporcionada por cada entrevistado. 


\section{INTRODUCCIÓN}

La Tabla 1, muestran los datos referentes a las características taxonómicas: Familia, Nombre Científico y común; así como de los caracteres etnomedicinales: parte utilizada, forma de preparación y usos Medicinales de las
44 especies de plantas medicinales utilizadas por el poblador del distrito de Huanchaco; vislumbrando a su vez en las figuras 2 y 3 , su distribución en 22 familias y 42 géneros.

\section{Tabla 1}

Flora medicinal empleada por el poblador del Distrito de Huanchaco, Trujillo, La Libertad, Perú

\begin{tabular}{|c|c|c|c|c|c|}
\hline № & $\begin{array}{l}\text { NOMBRE CIENTÍFICO/ } \\
\text { FAMILIA }\end{array}$ & $\begin{array}{l}\text { NOMBRE } \\
\text { COMÚN }\end{array}$ & $\begin{array}{c}\text { PARTE } \\
\text { UTILIZADA }\end{array}$ & $\begin{array}{c}\text { FORMA DE } \\
\text { PREPARACION }\end{array}$ & USOS MEDICINALES \\
\hline 1 & $\begin{array}{l}\text { Dysphania ambrosioides } \\
\text { (L.) Mosyakin \& Clemants/ } \\
\text { AMARANTHACEAE }\end{array}$ & "paico" & hoja y tallo & $\begin{array}{l}\text { infusión, } \\
\text { extracto } \\
\text { alcoholico }\end{array}$ & $\begin{array}{l}\text { Antiseptico, antipirética, insecticida, } \\
\text { emenagoga, antidiabetica, antitusígena, } \\
\text { antiescorbútica, astringente, cólicos, } \\
\text { estomáquica, digestiva, carminativa, tónica, } \\
\text { diurética, antihemorroidal, antihelmíntica. }\end{array}$ \\
\hline 2 & $\begin{array}{l}\text { Allium sativum (L.) } \\
\text { AMARYLLIDACEAE }\end{array}$ & "ajo" & bulbo & $\begin{array}{l}\text { jarabe, } \\
\text { decocción, } \\
\text { ensaladas, } \\
\text { cataplasmas, } \\
\text { infusión, } \\
\text { tintura, } \\
\text { cocimiento }\end{array}$ & $\begin{array}{l}\text { Contra los oxiuros intestinales, exitante, } \\
\text { rubefaciente, vermífugo, antiespasmodico, } \\
\text { vasodilatador, hipertensión, dispepsia, } \\
\text { bronquitis crónica, difteria, tuberculosis, } \\
\text { diurético, expectorante. }\end{array}$ \\
\hline 3 & $\begin{array}{l}\text { Schinus molle (L.) } \\
\text { ANACARDIACEAE }\end{array}$ & "molle" & $\begin{array}{l}\text { hoja y } \\
\text { corteza }\end{array}$ & $\begin{array}{l}\text { jugo, tintura, } \\
\text { parches, } \\
\text { soasadas }\end{array}$ & $\begin{array}{l}\text { Contra enfermedades renales, reumatismo, } \\
\text { cefalagia, "susto", purgante, astringente, } \\
\text { emenagoga, diurético, diarrea, leucorrea, } \\
\text { dolor de garganta, colagoga, cicatrizante, } \\
\text { hidropesia, dolor de piernas, depurativo de la } \\
\text { sangre }\end{array}$ \\
\hline 4 & $\begin{array}{l}\text { Apium graveolens (L.) } \\
\text { APIACEA }\end{array}$ & "аріо" & $\begin{array}{l}\text { toda la } \\
\text { planta }\end{array}$ & $\begin{array}{l}\text { tintura, } \\
\text { hortaliza, } \\
\text { infusión }\end{array}$ & $\begin{array}{l}\text { Diurético, estimulante, expectorante, tónico, } \\
\text { aperitivo, carminativo, febrífugo, antipaludico, } \\
\text { queratoplástico, emenagogas, neurastenia, } \\
\text { hidropesia, reumatismo, artritis. }\end{array}$ \\
\hline 5 & $\begin{array}{l}\text { Petroselinum crispum (Mill.) } \\
\text { Fuss/ APIACEA }\end{array}$ & "perejil" & $\begin{array}{l}\text { toda la } \\
\text { planta }\end{array}$ & $\begin{array}{l}\text { cocimiento, } \\
\text { infusión, } \\
\text { cataplasmas }\end{array}$ & $\begin{array}{l}\text { Digestivo, emenagogo, estomáquico, } \\
\text { febrífugo, aperitivo, resolutivo, carminativo, } \\
\text { alcalinizante, espectorante, diurético, } \\
\text { afrodisiaco, estimulante uterino, infalmación } \\
\text { de vejiga y riñones, ulceras, llagas, malaria. }\end{array}$ \\
\hline 6 & $\begin{array}{l}\text { Daucus aleppicus } \\
\text { J.Thiébaut/ APIACEA }\end{array}$ & "zanahoria" & $\begin{array}{l}\text { raíces, } \\
\text { hojas, flores, } \\
\text { semillas }\end{array}$ & $\begin{array}{l}\text { emplastos, } \\
\text { machacados, } \\
\text { cocimientvo, } \\
\text { infusión, fresco }\end{array}$ & $\begin{array}{l}\text { Laxante, vitalizante, digestivo, mineralizante, } \\
\text { refrescante, expectorante, antiseptico, } \\
\text { depuratico, antiflatulencias, antiescorbútico, } \\
\text { antihelmíntico, diurético, amenorrea, } \\
\text { reumatismo, raquitismo, acidosis, hidropesia, } \\
\text { ictericia, gota, tuberculosis, anemia y } \\
\text { enfermedades bronquiales. }\end{array}$ \\
\hline 7 & $\begin{array}{l}\text { Nerium oleander L./ } \\
\text { APOCYNACEAE }\end{array}$ & $\begin{array}{l}\text { "laurel } \\
\text { rosa" }\end{array}$ & hoja & $\begin{array}{l}\text { cocimiento, } \\
\text { infusión, látex }\end{array}$ & $\begin{array}{l}\text { Diurético, estimulante de la circulación, } \\
\text { narcótico, cardiotónico, piojos, afecciones de } \\
\text { la piel y cuero cabelludo, eczemas, úlceras } \\
\text { atónicas, hepes, tiña. }\end{array}$ \\
\hline
\end{tabular}


8

Tagetes pusilla Kunth/ ASTERACEAE

"anis

toda la

planta

infusión cocimiento

9 Sonchus oleraceus (L.) L./ "cerraja" tallo y hojas
ASTERACEAE

infusión, emplastos

Matricaria recutita L./ ASTERACEAE

"manzanilla" hoja y flores

infusión, cocimiento

Senecio canescens (Humb.

11 \& Bonpl.) Cuatrec./
ASTERACEAE

"vira vira" hojas

12

Tiquilia dichotoma (Ruiz \&
Pav.) Pers./ BORAGINACEAE

Cordia lutea Lam./ BORAGINACEAE

Raphanus sativus L./ BRASSICACEAE

"rábano"

raíz

cocimiento, ensaladas

tintura, cocimiento, infusión CAPRIFOLIACEAE "valeriana"

Cucurbita pepo L./ CUCURBITACEAE EQUISETACEAE

Erythroxylum

novogranatense

(D.Morris) Hieron ERYTHROXYLACEAE

\section{"cola de toda la} caballo" jugo, polvo, emplasto, al natural

cocimiento
Carminativa, lavado de heridas malignas, antiabortiva, colagoga, digestiva, sedante y gástrico.

Afecciones hepáticas, antidiarreico, antiespasmódica, carminativa, depurativa, disentería, hemoliente, estomáquica enfermedades de la piel, hepatitis, inflamación, úlceras estomacales.

Antialérgico, antiespasmódico, sedante, tónico, digestivo, febríguga, antineurálgica, cólicos, flatulencias, reumatismo, cistitis, hemorroides, conjuntivitis, dolor de oído.

Antitusígena, sudoríficas, diurética, depurativa, expectorante, enemagogo, inflamación de vejiga y próstata.

Depurativa, diurética, sedante, artritis, reumatismo, antialérgica, riñones, estómago, sistema nervioso y linfático.

Enfermedades hepáticas y renales.

Aperitivo, antiescorbútico, alcalinizante, oxidante, mineralizante, calmante, diurético, reumatismo, gota, artritis, bronquitis, resfriados, inflamciones internas, coletiasis, erupciones cutáneas, disolvente de cálculos biliares.

Agotamiento, antiasmátca, antiespasmódica calmante nervioso, cefalagia, insomnio, dispepsia, jaqueca, migraña, sedante, estrés, enfermedades del riñon y vías respiratorias.

Dolor de oído, estómago, vermífuga, febrífuga, erisipela, inflamación de vías urinarias, antihelmíntico.

Afecciones hepáticas, afecciones de la boca y garganta, pulmones y vejiga, antianémica, antiasmática, astringente, bronquitis, cálculos biliares y renales, gripe, forúnculos, estimulante, tuberculosis, útero y varices.

infusión, decocción, emplasto, "cacchada", cataplasma
Narcótico, anestécico, estimula el sistema nervioso, favorece actividad física, antiespasmódica, calmante, tónico, vómitos asma, insomnio, delirio, mal de altura, reumatismo, dolor de cabeza 
19

$$
\begin{gathered}
\text { Croton palanostigma } \\
\text { Klotzsch/ }
\end{gathered}
$$
EUPHORBIACEAE

\title{
"sangre de
} grado"

corteza

\section{DPORBIACEAE}

20

\author{
Mentha viridis (L.) L. /
} LAMIACEAE

21

$$
\begin{aligned}
& \text { Mentha } \times \text { piperita L. / } \\
& \text { LAMIACEAE }
\end{aligned}
$$
LAMIACEAE

\section{Origanum vulgare L. /} LAMIACEAE

infusión

fresco, con agua, jugos, leche, directo

infusión, cocimiento

\section{Melissa officinalis L. / LAMIACEAE} LINACEAE

Caesalpinia spinosa (Molina) Kuntze/ LEGUMINOSAE "toronjil"

toda la planta

toda la planta $\begin{array}{ll}\text { "tara" } & \text { fruto y } \\ \text { semilla }\end{array}$

"linaza"

semilla

oja, látex y fruto
Infusión, baños

pomadas, infusión

maceración, dección, semillas enteras, papillas, cataplasmas

emplastos, cocimiento, colutorios, gargarismos, compresas
Cicatrizante de heridas superficiales úlceras gástricas, astringente, hemostático, antiséptico, antiinflamatorio, gingivitis, cervicitis, descongestionante.

Carminativa, digestiva, antiespasmódica estimulante de secreción biliar, antidiarreico.

Antiespasmódica, colagoga, tónica estimulante, exitante, dolor de cabeza, calambres, vértigos, catarro, digestiva, carminativa.

Tónico estomacal, estimulante biliar, carminativa, laringitis, amigdalitis, antiespasmódico, digestivo, resfriado, asma, ciática, artritis, reumatismo, afecciones hepáticas, astringente, afecciones de la vejiga, catarro, dolor de muela, emenagogo.

Carminativa, estimulante, estomacal, diaforética, antiespasmódica, sedante, insomnios, digestivo.

Carminativa, estimulante, estomacal, diaforética, antiespasmódica, sedante, insomnios, digestivo.

Antianémica, antihemorrágica, recalcificante, escorbuto, raquitismo, digestivo, insomnio neurastenia, reumatismo, artritis, inapetencia, crisis crónica.

Amigdalitis, astringente, desinfectante, reductora, sinusitis, cicatrizante de heridas externas.

Antidiabética, antiinflamatoria, estomacal, laxante, úlceras, forúnculos, afecciones renales, afecciones de la boca y garganta, cálculos biliares, hiperacidéz gástrica estreñimiento, inflamación del sistema digestivo y de las vías urinarias.

Energético, resfriado, gripe, faringitis, bronquitis, asma, anticaspa, antidiabético, antidiarreico, antitusígena, callicida, diurética, hemoliente, enfermedades del riñon, piel, hígado y estómago, hinchazones, colitis, laxante, vermífuga.

Tuberculosis, antiofídico, antiverrucoso, antigripal, afecciones hepáticas, antianémica, antiasmática, antibiabética, antidiarreica antirreumático, antihemorrágica, astringente, bronquitis, cálculos biliares, cálculos renales. 
Cymbopogon citratus (DC.) Stapf/ POACEAE

Malus communis var.

\section{"uña de} gato" raíz, tallo, corteza cocimiento,

infusión,

inhalación,

ungüentos,

cataplasmas,

baños, lociones,

frotaciones

infusión, cocimiento, cataplasma maceración

perladas 0 germinadas,

harina,

decocción

cocimiento, infusión, jugo

RUBIACEAE consumo

directo,

infusión,

decocción

cocimiento decocción, emplasto

\begin{abstract}
Afecciones biliares, de la boca y garganta, afonía, amigdalitis, angina de pecho, antiasmática, antipalúdica, antipirética, antirreumática, antiséptica, desinflamante, diaforética, vías respiratorias, expectorante, gripe, neumonía, sedante.
\end{abstract}

Paludismo, espermatorrea, estomacal, depurativo sanguíneo, antipirético, mucolítico, antihelmíntico, diurético, contusiones, desinflamante de heridas, estreñimiento, fiebre amarilla, cálculos biliares, rabia, tranquilizante, úlceras.

Analgésico, astringente, acné, afecciones hepáticas, de la boca, garganta, antidiabética, antihemorrágica, antipirética, antirreumática, artritis, cefalagia, conjuntivitis, forúnculos, desinflamante, quemaduras, sarna, úlceras estomacales.

Antidiarreico, cardiotónico, hipolipemiante, diurético, arteriosclerosis, hipotensión, cistitis, litiasis renal, diabetes, antiespasmódica, reduce el colesterol, emoliente, astringente, antifebril, bronquitis.

Digestivo, estomacal, carminativo antidiarreico, antiespasmódica, antihelmíntico, antihemorroidal, antirreumático, antiséptico, analgésico, dismenorrea, inflamación de vías urinarias.

Diurético, desinfectante de las vías urinarias, fiebre, enfermedades cardiácas, gota, afecciones renales, dismenorrea, cálculos renales, cólicos, cistitis

Sudorífica, diurética, cálculos hepáticos.

Antiácida, antidiabética, antidiarreica antipirética, antirreumática, calambres, cálculos biliares, colagoga, estimulante del apetito, estimulante de secreción pancreática, estreñimiento, flatulencias, gastritis, gripe, hemorroides, insomnio, intestino, laxante, obesidad, pleuresía, refríos, sinusitis, sistema nervioso, úlceras estomacales.

Antiinflamatorio, antioxidante, activael sistema inmunológico, artritis, anticancerígeno, antirreumático, debildad, depurativo, descensos, disentería, desequilibrio hormonal, diurético, úlceras estomacales, recuperación de parto, mordedura de serpiente, previene gripes y resfríos. 
raíz, fruto, aceite

cocimiento, jugo, zumo

hojas, flores, fruto

tintura, tisana, zumo, infusión, jugo
41

\begin{tabular}{|c|c|}
\hline $\begin{array}{c}\text { Ruta graveolens L./ } \\
\text { RUTACEAE }\end{array}$ & "ruda" \\
\hline
\end{tabular}
SOLANACEAE

Aloe vera (L.) Burm.f./ XANTHORRHOEACEAE extracto cuoso, tópico, baños infusión, cocimiento, extractos, tinturas, cremas jugo cocimiento, maceración, tintura, cataplasma
Anticaspa, antiespasmódica, febrífugo, sarampión, descongestionante, sedante, calambres, enteritis, acné, afonía, resfríos, gripe, acidéz bucal y estomacal.

Estimulante del apetito y la digestión, resfrescante, astringente, antiséptico, hemostático, acidéz gastrica, acné, adenitis, afonía, aftas, amenorrea, amigdalitis, analgesia, anemia, angina de pecho, ántrax apendicitis, apoplejia, arteriosclerosis, artritismo, asma, astenia, beriberi, blenorragia, bocio, broncopulmonía, calambres, cálculos, caspa, catarro, ciática, virosis, conjuntivitis, rematismo, coriza, diabetes, difteria, dismenorrea, estomatitis, faringitis, heridas, fiebre, fístulas, gota, hepatitis, hemoptitis, hemorragias, hemorroides, traumatismo, tuberculosis, úlceras gastricas, toxemia, uremia, uretritis, viruela, lombrices intestinales, vómitos y zumbidos.

Analgésica, anestésica, abortiva, ansiedad nerviosa, antiespasmódica, antihemorrágica, antirreumática, carminativa, cefalagia, cólicos, contra el aire, diaforética, digestiva, dispepsia, diurética, dolor de muela, dolor de oídos, hidropesía, hinchazón, mareos, migraña.

Desinflamante, calmante, analgésica, úlceras, espasmolítico, antiácido, afecciones hepáticas, antirreumática, artritis, cálculos renales, cefalagia, cistitis, colitis, diabetes, diurética, enfermedades de la piel, riñon y vejiga, próstata.

Úlceras intestinales y estomacales, disminuye la acidéz, analgésico, antifebril, cicatrizante, tónico digestivo, colagogo, laxante, vulnerario, estreñimiento, transtornos hepáticos, inflamación, quemaduras, eczemas, erisipela, conjuntivitis, ojos irritados, heridas, odontálgico, tos, hemorroides.

Diurético, carminativa, estimula la secreción del jugo gastrico, apetito, flatulencias, antidispéptico, antiséptico, expectorante, antiespasmódico, úlceras crónicas, tos, bronquitis, resfriados, catarros crónicos, asma, ronquera, expectorante, antihemorroides. 


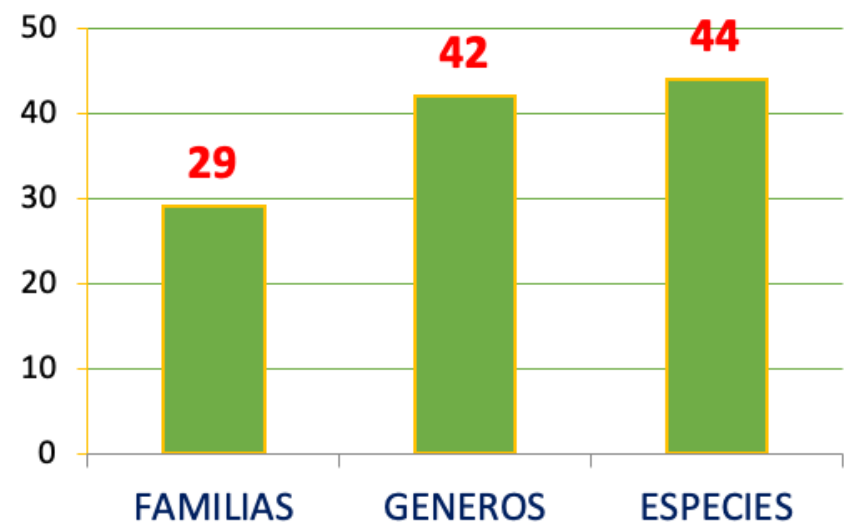

Figura 2. Distribución Taxonómica en Familias y Géneros de la Flora medicinal empleada por el poblador del distrito de Huanchaco, Trujillo, La Libertad, Perú

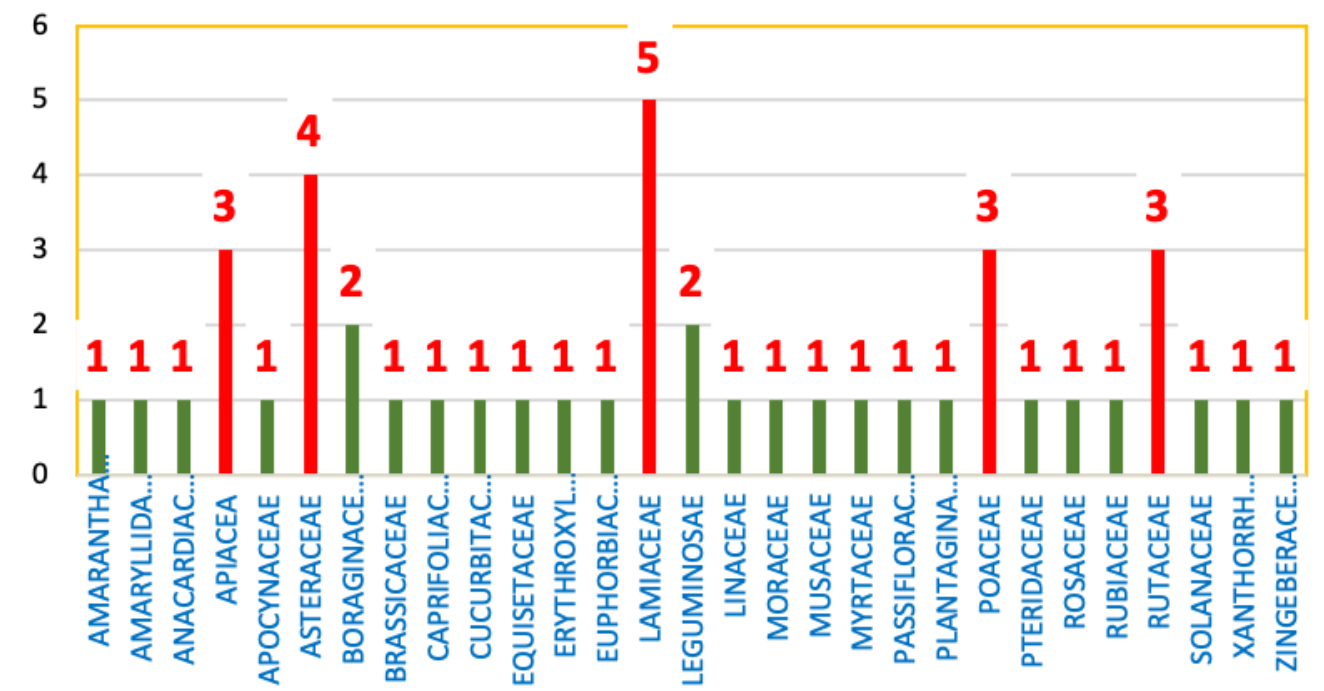

Figura 3. Número de Especies por Familia de la Flora medicinal del distrito de Huanchaco, Trujillo, La Libertad, Perú

\section{DISCUSIÓN}

Hoy en día se conoce de muchos trabajos realizados sobre la Fitodiversiad Peruana, de allí que autores como Dourojeanni (1982), Picard y Villar (1982), Pretell et al., (1985), Sagástegui (1995), entre otros detallan específicamente el carácter taxonómico de muchas especies de flora Local, Reginal y Nacional; más no se conoce acerca de sus características etnobotánicas; de allí que pocos son los trabajos que aportan conocimiento en este ámbito de la botánica, notándose en la escasa difusión de los conocimientos en lo concerniente a las características etnomedicinales; Por lo que es imprescindible sentar las bases para posteriores investigaciones dentro de esta área; de allí que se reporta para esta investigación (Fig. 2 y 3) un total de 44 especies de plantas utilizadas desde tiempos inmemoriales, distribuidas en 29 Familias y 42 géneros, que de alguna u otra forma representa una herencia para el poblador Peruano en general y el del Distrito de Huanchaco en particular; lo que concuerda con Tovar (2001), quien afirma que el antiguo poblador peruano desde tiempos muy remotos 
conocía el correcto y eficaz uso de las plantas medicinales.

En cuanto a la Tabla 2 y Figura 3, destacan por su número de especies las Lamiaceae (05 especies), representadas por: Mentha viridis (L.) L. "hierba buena", Mentha × piperita L. "menta", Origanum vulgare L. "oregano", Salvia officinalis L. "salvia", Melissa officinalis L. "toronjil"; seguido de las Asteraceae (04 especies), representados por: Tagetes pusilla Kunth "anis serrano", Sonchus oleraceus (L.) L. "cerraja", Matricaria recutita L. "manzanilla", Senecio canescens (Humb. \& Bonpl.) Cuatrec. "vira vira", y las Apiaceae, Poaceae y Rutaceae ,con 03 especies cada una, estando representadas las Apiaceae por: Apium graveolens L. "apio", Petroselinum crispum (Mill.) Fuss "perejil", Daucus aleppicus J.Thiébaut "zanahoria", las Poaceae por: Hordeum vulgare L. "cebada", Cymbopogon citratus (DC.) Stapf "hierba luisa", Zea mays L. "maíz" y las Rutaceas por: Citrus limetta Risso "lima", Citrus x limonum Risso "limón", Ruta graveolens L. "ruda"; especies que de alguna u otra forma se hallan relacionadas en cuanto a su uso en la Provincia de Trujillo en general y en otros Distritos, como el Porvenir en Particular; de allí que Bussman et al., (2007), reportó para el Porvenir el uso de 38 especies, siendo las especies más utilizadas para ese Distrito: Matricaria frigidum "manzanilla", Piper aduncum "matico", Equisetum bogotense "cola de caballo", Eucalyptus globulus "eucalipto", Plantago major "llantén", Linum usitatissimum "linaza", Aloe vera "sábila", Cymbopogon citratus "hierba luisa", Foeniculum vulgare "hinojo", Peumus boldus "boldo", Hordeum vulgare "cebada", Phyllanthus niruri, Phyllanthus stipulatus "chanca piedra", Buddleja utilis "flor blanca", Uncaria tomentosa "uña de gato" y Urtica magellanica entre otras; lo que vislumbra el alto grado de relación en cuanto al uso de plantas medicinales entre ambos Distritos, como son Huanchaco y el Porvenir.

Por otro lado, el hecho de que tanto las familias Lamiaceae y Asteraceae resultaran siendo las más representativas (Tabla 1 ). Se deba problamente a su amplio rango de distribución y al cuantioso número de metabolitos secundarios que poseen; lo que concuerda con
Bussmann y Sharon (2015), Alipio et al. (2020), De La Cruz et al. (2020), Magno et al. (2020) y Mostacero et al. (2020c); quienes corroboraron que las Lamiaceae y Asteraceae están entre las familias mayormente empleadas en la medicina tradicional.

Lo descrito en el párrafo anterior, se afianza aún más con las investigaciones realizadas por Zielinska y Michalska (2016), Castillo et al. (2019), Lara et al. (2019), Silva et al. (2019), Alipio et al. (2020), De La Cruz et al. (2020), Magno et al. (2020) y Mostacero et al. (2020c), quienes catalogan a las Asteraceae, Lamiáceas presentan vitaminas, sales minerales y antioxidantes; de allí que las personas del distrito de Huanchaco atribuyen a estas especies la capacidad de curar y/o alivio a las afecciones hepáticas, de la vejiga, así un efecto antidiarreico, antiespasmódico, carminativo, depurativo, estomáquico, hemoliente, disentería, así como combatir enfermedades de la piel, orzuelos, inflamación, úlceras estomacales, laringitis, amigdalitis, tortícolis, resfriado, asma, ciática, artritis, reumatismo, astringente, carminativa, catarro, dispepsia, dolor de muela, emenagogo, así como falta de apetito, y como sedante (Tabla $1)$.

Finalmente es importante recalcar que urge realizar investigaciones del tipo básicas, como las relacionadas a los aspectos biogeográficos; toda vez que este tipo de investigaciones son la base angular para proponer futuros programas y/o proyectos de Conservación y/o restauración de la flora medicinal; de allí que según Mostacero et al., (2007) afirma que el saber taxonómico, implica conocer donde viven las plantas; esto se logra con las exploraciones botánicas y por ende la herborización, con tareas de campo que permitan conocer "in situ" a las plantas, y con ello el tipo de suelo, clima, etc.; es decir su ecología; a fin de generar ideas para Conservar estas especies promisorias, a la par de sentar las bases para la realización de futuras investigaciones de índole aplicado. 


\section{CONCLUSIONES}

Se reportan 44 especies de plantas medicinales empleadas por el poblador del distrito de Huanchaco; distribuidas en 22 familias y 42 géneros, de las que destacan por el número de especies: Lamiaceae (5), Asteraceae (4), y Rutaceae (3), Poaceae (3), Apiaceae (3).

Es imprescindible promover el uso de la flora medicinal propia del distrito de Huanchaco, a la par de fomentar la implementación de programas de conservación, tendientes a buscar la sostenibilidad y sustentabilidad de estos recursos promisorios; que traten de evitar la pérdida de este conocimiento ancestral, para beneficio de las futuras generaciones del distrito de Huanchaco en particular y del Perú y el mundo en general.

\section{REFERENCIAS BIBLIOGRÁFICAS}

Agenda 21. (2003). Plan Estratégico de Desarrollo Integral y Sostenible de Trujillo. Resumen Ejecutivo. Actualizada a 2003. Trujillo- Perú.

Albújar-Baca, P. (2014). Mortalidad por cáncer en Trujillo: 2003-2010. Acta Med Per. 31(3):150-156. Disponible en: $\quad$ http://www.scielo.org.pe/ $p d f / a m p / v 31 n 3 / a 03 v 31 n 3 . p d f$

Alipio, A.; Mostacero, J.; López, E.; De La Cruz, A.; Gil A. (2020). Valor de uso etnomedicinal de la flora del Cerro "La Botica" empleada por la Comunidad Andina de Cachicadán - Perú. Bol Latinoam Caribe Plant Med Aromat. 19(6): 601 - 613.

Annan, K.; Houghton, P. (2007). Antibacterial, Antioxidant and Fibroblast Growth Stimulation of Aqueous Extracts of Ficus asperifolia Miq and Gossypium arboreum L., Wound-healing Plants of Ghana. Journal of Ethnopharmacology 119: 141144. DOI: 10.1016/j.jep.2008.06.017

Bailey, K. (1994). Methods of Social Research. Ed. TheFreePress, New York, USA.

Bhat, R.; Paliyath, G. (2016). Fruits of Tropical
Climates: Dietary Importance and Health Benefits. Reference Module in Food Science, from Encyclopedia of Food and Health: 144-149.

Bocanegra, L.; Bocanegra, F.; Mostacero, J. (2011). Efectividad de la medicina herbolaria y su impacto en la calidad de vida de los pobladores de Curgos, Perú. UCV Scientia 3(1): 23-34. http://repebis.upch. edu.pe/articulos/ucvsci/v3n1/a3.pdf

Boeing, H.; Bechthold, A.; Bub, A.; Ellinger, S.; Haller, D.; Kroke, A.; Leschik-Bonnet, E.; Müller, M.; Oberritter, H.; Schulze, M.; Stehle, P.; Watzl, B. (2012). Critical review: vegetables and fruit in the prevention of chronic diseases. Eur J Nutr 51(6): 637663. DOl: 10.1007/s00394-012-0380-y

Brako, L.; Zarucchi, J. (1993). Catálogo de las Angiospermas y Gimnospermas del Perú. Monogr. Syst. Bot. Missouri Bot. Garden. Vol 45.

Bruneton, J. (2001). Farmacognosia. Fitoquimica. Plantas Medicinales 2da Edición. Ed. Acribia S.A.: Zaragoza. España.

Bussmann, R.; Sharon, D.; Lopez, A. (2007). Blending Traditional and Western Medicine: Medicinal plant use among patients at Clinica Anticona in El Porvenir, Peru. Ethnobotany Research \& Applications. 5:185-199. DOI:10.17348/era.5.0.185-199

Bussmann, R.; Sharon, D. (2015). Plantas medicinales de Los Andes y la Amazonia - La Flora mágica y medicinal del Norte del Perú. Graficart SRL, Trujillo, Perú. Disponible en: https://docs. bvsalud.org/biblioref/2018/10/916684/ plantas-medicinales-de-los-andes-y-laamazonia-la-flora-magica-_Qa3dgqr.pdf

Catillo, H.; Albán, J.; Castañeda, R. (2019). Importancia cultural de la flora silvestre de la provincia de Cajabamba, Cajamarca, Perú. Arnaldoa 26(3): 1047-1074. DOl: http:// dx.doi.org/10.22497/arnaldoa.263.26313 
De La Cruz, A. y Mostacero, J. (2019). Uso de plantas medicinales para la cura de enfermedades $\mathrm{y} / \mathrm{o}$ dolencias: $\mathrm{El}$ caso del poblador de la provincia de Trujillo, Perú. Manglar 16(2): 119-124.

De la Cruz, J.; Gómez, J.; Chanco, M.; et al. (2020). Flora y vegetación de la provincia de Huamanga (Ayacucho-Perú). J Selva Andina Biosphere 8(1):3-18. https://doi. org/10.36610/j.jsab.2020.080100003

Dourejeanni, M. (1982). Recursos Naturales y Desarrollo en América Latina y el Caribe. Edit. Universidad de Lima. Lima - Perú.

Freedman, D.; Peña, N.; Friedman, D.; Ory, M.; Flocke, S.; Barni, M.; Hébert, J. (2014). Extending Cancer Prevention to Improve Fruit and Vegetable Consumption. $J$ Cancer Educ 29(4): 790-795. DOl: $\quad$ 10.1007/s13187-014-0656-4

Gil, A.; Lopéz, E.; Mostacero, J.; De La Cruz, A. (2019). Papas nativas con potencial antioxidante, cultivadas en el norte del Perú. Bol Latinoam Caribe Plant Med Aromat. 18(3): 289-324. DOI: https:// doi.org/10.37360/blacpma.19.18.3.19

INEI (Instituto Nacional de Estadística e Informática). (2018). Perú: Resultados definitivos. Tomo I. Lima, Perú.

Jatinder, P.; Amritpal, K.; Narpinder, S.; Lovedeep, N.; Khetan, S.; Harpreet, K.; Daljit, S. 2016. In vitro antioxidant and antimicrobial properties of jambolan (Syzygium cumini) fruit polyphenols. LWT-Food Science and Technology 65: 1025-1030.

Lara, E.; Fernández, E.; Zepeda, J.; Lara, D.; Aguilar, A.; Van Damme, P. (2019). Etnomedicina en Los Altos de Chiapas, México. Bol Latinoam Caribe Plant Med Aromat. 18 (1): 42-57.

Magadi, R.; Arpitha L.; Kumaraswamy, M. (2015). Evaluation of cytotoxicity of aqueous extract of Graviola leaves on squamous cell carcinoma cell-25 cell lines by 3-(4,5-dimethylthiazol-2-Yl)

-2,5-diphenyltetrazo-lium bromide assay and determination of percentage of cell inhibition at G2M phase of cell cycle by flow cytometry: An in vitro study. Contemp Clin Dent 6(4): 529-533.

Magno, E.; Teixeira, T.; Tavares, A. (2020). Ethnobotany and ethnopharmacology of medicinal plants used in communities of the Soure Marine Extractive Reserve, Pará State, Brazil. Bol Latinoam Caribe Plant Med Aromat, 19 (1): 29-64.

Mannarino, M.; Ministrini, S.; Pirro, $M$. (2014). Nutraceuticals for the treatment of hyperchol-esterolemia. European Journal of Internal Medicine 25(7): 592-599.

Martin, G. (2005). Etnobotánica: Manual y Métodos. Fondo Mundial para la Naturaleza (WWWF-UK), Unesco, Royal Botanical Garden.

Mostacero, J. (2017). Rol de la biodiversidad: Importancia alimenticia para el desarrollo del Perú. Revista De Investigaciones De La Universidad Le Cordon Bleu 4(1): 63-70.

Mostacero, J.; Castillo, F.; Mejía, F.; Gamarra, O.; Charcape, J.; Ramírez, R. (2011). Plantas Medicinales del Perú: Taxonomía, Ecogeografía, Fenología y Etnobotánica. lera Edición. Editorial Asamblea Nacional de Rectores Fondo Editorial. Trujillo, Perú. 909 pp.

Mostacero, J.; Gonzales, C.; De La Cruz, A.; et al. (2020a). Flora medicinal empleada en el tratamiento de enfermedades padecidas por el poblador del distrito de Trujillo, Peru. Rev. Tayacaja 3(1): 126-140.

Mostacero J, Lopez S, De La Cruz A, Gil A, Alva R, Charcape M. (2020b). "Plantas frias" y "Plantas calientes" recursos potenciales en la prevencion y/o tratamiento del COVID- 19. Manglar 17(3): 209-220.

Mostacero, J.; De La Cruz, A.; Lopez, E.; Gil, A.; Alfaro, E. (2020c). Efecto de la medicina 
herbolaria en la calidad de vida: inventario de especies etnomedicinales y percepcion del poblador de Laredo, Peru Agroind Sci. 10(2): 181-190.

Mostacero, J.; Mejía, F.; Gamarra, O. (2009). Fanerógamas del Perú: Taxonomía, utilidad y eco geografía. lera Edición. Editorial CONCYTEC. Trujillo, Perú. 1331 pp.

Mostacero, J.; Mejía, F.; Zelada, W.; Medina, C. (2007). Biogeografía del Perú. Asamblea Nacional de Rectores. Trujillo - Perú.

Mostacero, J.; Peláez, F.; Alarcón, N.; De La Cruz, A.; Alva, R.; Charcape, M. (2019). Plantas utilizadas para el tratamiento del cáncer expendidas en los principales mercados de la provincia de Trujillo, Perú, 2016 - 2017. Bol Latinoam Caribe Plant Med Aromat, 18(1): 81-94.

Picard, L. y Villard, M. (1982). Metodología Utilizada Para la Introducción de Especies Forestales en Cajamarca - Perú. №3. Edit. Centro de Investigación y Capacitación Forestal. CICAFOR. Cajamarca - Perú.

Pretell, J.; Ocaña, D.; R. Jon.; Barahona, E. (1985). Apuntes Sobre Algunas Especies Forestales Nativas de la Sierra Peruana. Proyecto FAO/Holanda/ INFOR. Edit. Centauro S.A. Lima - Perú.

Sagástegui, A. (1995). Diversidad Florística de Contumazá. Fondo Editorial Univ. Antenor Orrego. Edit. Libertad. Trujillo - Perú.

Ramírez, L.; Mostacero, J.; López, E.; De La Cruz, A.; Gil, A. (2020). Aspectos etnobotánicos de Cuspón, Perú: Una comunidad campesina que utiliza 57 especies de plantas en sus diversas necesidades. Scientia Agropecuaria 11(1): 7-14.

Shigihara, M.; Obara, T.; Nagai, M.; Sugawara, Y.; Watanabe, T.; Kakizaki, M.; Nishino, Y.; Kuriyama, S.; Tsuji, I. (2014). Consumption of fruits, vegetables, and seaweeds (sea vegetables) and pancreatic cancer risk: The Ohsaki Cohort Study.
Cancer Epidemiology38(2): 129-136.

Silva, J.; Cabrera, J.; Trujillo, O.; et al. (2019). Características de las plantas medicinales comercializadas en diferentes mercados de Lima Metropolitana y sus efectos sobre el medio ambiente y la salud pública. Horiz Med (Lima) 19(4): 63-69.

Tovar, O. (2001). Plantas Medicinales Del ValleDelMantaro. MuseodeHistoriaNatural. Universidad San Marcos. Multicopy. 7: 13-17.

Wang, P.; Fang, J.; Gao, Z.; Zhang, C.; Xie, S. (2016). Higher intake of fruits, vegetables or their fiber reduces the risk of type 2 diabetes: A metaanalysis. J Diabetes Investig 7(1): 56-69.

Zielinska, M. y Michalska, A. (2016). Microwaveassisted drying of blueberry (Vaccinium corymbosum L.) fruits: Drying kinetics, polyphenols, anthocyanins, antioxidant capacity, colour and texture. Food Chem 212: 671-680. 